\title{
Association Between Anterior Chamber Angle and Corneal Endothelial Cell Density in Chronic Angle Closure
}

\author{
Iwan Soebijantoro' \\ Tjahjono D Gondhowiardjo' \\ Marsetyawan Soesatyo ${ }^{2}$ \\ 'JEC Eye Hospitals and Clinics, Jakarta, \\ Indonesia; ${ }^{2}$ Faculty of Medicine, \\ Universitas Gadjah Mada, Yogyakarta, \\ Indonesia
}

Purpose: To study the association between corneal endothelial cell density (ECD) and degree of anterior chamber angle (ACA) opening in eyes with chronic angle closure glaucoma.

Methods: The study was conducted at JEC Eye Hospitals in Indonesia. Treatment-naïve patients aged $\geq 40$ years with IOP $>21 \mathrm{mmHg}$ and peripheral anterior chamber depth (ACD) grade 2 or less by Van Herick's technique were recruited. Trabecular iris angle (TIA; degree) was measured using anterior segment optical coherence tomography (AS-OCT) and classified as: grade $1 \leq 10^{\circ}$, grade $211-20^{\circ}$, and grade $3>20^{\circ}$. Noncontact specular microscopy was performed, and the following corneal parameters were obtained:ECD (cells $/ \mathrm{mm}^{2}$ ), coefficient of variation $\left(\mathrm{CV} ; \mu \mathrm{m}^{2} /\right.$ cell), percentage of hexagonal cells, and central corneal thickness (CCT; $\mu \mathrm{m})$.

Results: A total of 52 eyes from 52 subjects were recruited (16 grade 1 TIA, 24 grade 2 TIA, and 12 grade 3 TIA). Presenting IOP was not significantly different between groups. The median central corneal ECD was 2684.5 (1433-2934), 2587.0 (1902-3103), and 2441.0 (1659-3005) cells $/ \mathrm{mm}^{2}$ in grade 1,2 , and 3 TIA, respectively, with no significant differences across the groups $(P=0.67)$. The $\mathrm{CV}$ was lowest in grade 3 TIA $(36.4 \pm 7.2 \mu \mathrm{m} 2 /$ cell $)$, and highest in grade 1 TIA $(38.3 \pm 9.6 \mu \mathrm{m} 2 /$ cell $)$, but the differences were not significant $(P=$ 0.74). Likewise, the percentage of hexagonality and CCT was not significantly different. TIA was not correlated with IOP but was modestly correlated with age.

Conclusion: The corneal ECD and morphological characteristics such as CV and hexagonality were not significantly different across various TIA grading in chronic angle closure. This may reflect the lack of chronic and gradual IOP insult on corneal endothelial parameters as TIA did not show direct effect towards IOP.

Keywords: corneal endothelium, primary angle closure glaucoma; PACG, trabecular iris angle; TIA

\section{Introduction}

Glaucoma by itself - and its management such as medications, laser, and surgical procedures - is presumed to have damaging effects on the corneal endothelium. Endothelial cell loss has been reported in various types of glaucoma including primary angle closure glaucoma $(\mathrm{PACG})^{1,2}$ and following an acute angle-closure attack. $^{3-5}$ While it is crucial to preserve these cells as they lack regenerative ability, it is also important to understand risk factors associated with endothelial cell loss in glaucoma. Yet, there are a few conflicting studies which did not find such association of endothelial cell loss in glaucoma. ${ }^{6,7}$
Correspondence: Iwan Soebijantoro JEC Eye Hospitals and Clinics, Jalan Terusan Arjuna Utara Nomor I, Jakarta Barat, DKI, Jakarta, I I520, Indonesia Tel +62813 II020020

Email iwan@jec.co.id 
In acute angle closure glaucoma, the decrease in endothelial cell density (ECD) was related to the length of an acute attack and high IOP. ${ }^{8}$ Sihota et $\mathrm{al}^{1}$ found that acute PACG had significantly decreased ECD compared to subacute, chronic, and normal group, and $35.1 \%$ lower ECD compared to age-matched controls. Tham et $\mathrm{al}^{2}$ also found that acute PACG patients had an $11.6 \%$ reduction in ECD compared to their chronic angle-closure equivalents. They also demonstrated that the longer the duration of the acute attack, the greater the loss of ECD in that study.

However, even in the absence of acute attack, studies also reported lower ECD in narrow angle when compared to normal controls. Varadaraj et $\mathrm{al}^{9}$ compared the ECD in eyes with open angles and those with various stages of untreated angle closure disease. They found that primary angle closure suspects (PACS) eyes had lower ECD compared to eyes with open angles. Other study by Verma et $\mathrm{al}^{10}$ compared corneal ECD and morphological characteristics across primary angle closure disease spectrum and did not find any significant difference. They concluded that chronicity and the lack of dramatic IOP insult have a detrimental effect of no consequences on corneal endothelial parameters. However, prior literature has not examined whether the degree of anterior chamber angle (ACA) can have a direct effect on corneal endothelium in chronic angle closure even before procedures such as LPI and/or cataract surgery are performed in such eyes.

Visualization of ACA is essential in the diagnosis and treatment of glaucoma especially in narrow angles. Imaging instruments for anterior segment have been available for over two decades, and one of them is anterior segment optical coherence tomography (AS-OCT). ASOCT is a non-invasive technique acquiring highresolution images of the ACA which allows both quantitative and qualitative analyses. ${ }^{11}$ It can be performed easily, with relatively good repeatability and reproducibility, and provides excellent discriminative value for the detection of narrow angles. ${ }^{12,13}$ AS-OCT provides crosssectional images of the anterior segment by using lowcoherence interferometry. The interferometer can be based on the time (TD-OCT), the spectral (SD-OCT) or the swept source (SS-OCT) domain which is the most recent implementation of OCT using Fourier-domain technologies which allows circumferential assessment of the ACA with the fastest acquisition. ${ }^{11,14}$ Although not as fast as the newest technology of SS-OCT, spectral-domain systems have enhanced signal-to-noise ratio, image acquisition speed, and image resolution compared to time-domain ASOCT. ${ }^{15-17}$

The current study was conducted to determine whether an association exists between ACA and corneal ECD in chronic angle closure without prior surgery, iridotomy, or acute attack. ECD in chronic angle closure with varying degree of ACA was analyzed using specular microscopy in this study conducted in an Indonesian population.

\section{Materials and Methods Study Population}

This was a multi-hospital, same-institution, cross-sectional study that took place between January and July 2019 at the JEC Eye Hospital at Menteng and Kedoya in Jakarta, Indonesia. This study was reviewed and approved by the institutional review board of JEC Eye Hospital and Universitas Gadjah Mada, and study procedures conformed to the Declaration of Helsinki. Informed written consent was obtained from all participants before taking part in the study.

Sample size calculation was performed for correlation analysis and a minimum of 51 subjects was required. A convenience sampling method was used to recruit participants from glaucoma clinics at each center. Chronic angle closure glaucoma was defined as evidence of glaucomatous optic neuropathy accompanied by a rise in IOP due to obstruction of the outflow of the anterior chamber which presents painlessly without history of acute attack.

The inclusion criteria for this study were patients aged 40 years and above, IOP $>21 \mathrm{mmHg}$, peripheral anterior chamber depth (ACD) of grade 2 or less by Van Herick's technique, and no history of prior glaucoma medication or intervention (treatment-naïve). Individuals with: 1) history of ocular surgery; 2) symptoms or findings consistent with prior acute angle closure attack; 3) prior laser glaucoma procedures; and 4) signs of inflammation on adnexal tissue or other ocular tissue were excluded.

\section{Ophthalmological Assessment}

An initial interview was carried out to collect demographic data and relevant ocular history. All subjects then underwent a standardized ophthalmic examination that included visual acuity testing, slit lamp examination, IOP measurement with Goldmann applanation tonometry (GAT), stereoscopic evaluation of the optic disc, visual field testing, and optical coherence tomography (OCT) for optic nerve head evaluation and retinal nerve fiber layer (RNFL) 
thickness. All examinations were performed on the same day. One glaucoma specialist completed slit lamp biomicroscopy and GAT for IOP measurements on all subjects. GAT was performed three times on each eye and the averages were used for analysis.

A single trained technician performed AS-OCT and specular microscopy examinations. AS-OCT was done with Cirrus HD-OCT model 5000 (Carl Zeiss Meditec, Dublin, CA, US), which is an SD-OCT that uses 840-nm wavelength, with additional wide angle-to-angle external lens kit to image the entire anterior chamber of an eye. This HD-OCT utilized a $15.5 \times 5.8 \mathrm{~mm}$ angle-to-angle scan protocol and achieved a scan depth of $5.8 \mathrm{~mm}$ in high resolution by overlapping the source and mirror images. The scan line was adjusted manually to bisect the pupil. To acquire images of the unaccommodated eye, the focus of an internal-fixation target was adjusted with reference to the subject's refraction. The captured OCT image in the monitor screen was used as a guide, to ensure that there was no eye movement during the imaging (any eye movement would result in a distorted image). Each eye was measured at least three times. One image with clear visibility of the scleral spur was selected. ACAs with unclear scleral spurs were excluded in the analysis. All the images obtained had clear visibility of iris recess apex. The scleral spur was identified by a prominent inner extension of the sclera (its thickest part) and marked manually, then trabecular iris angle (TIA) was measured in all subjects. TIA was defined as an angle measured with the apex in the iris recess and the arms of the angle passing through a point on the trabecular meshwork $500 \mu \mathrm{m}$ from the scleral spur and the point on the iris perpendicularly. TIA was graded into the following classification: grade $1 \leq 10^{\circ}$, grade $211-20^{\circ}$, and grade $3>20^{\circ}$.

Noncontact specular microscope (NIDEK CEM-530, NIDEK Co., Ltd. Japan) was used to examine the central corneal endothelium. The device takes an image of $0.1 \mathrm{~mm}^{2}$ sized endothelial field. In total, 8 images are captured per scan. These images were presented and classified according to their quality directly after examination. Examiner chose a single best image according to endothelial cell contours with good contrast and sharp details that were clearly visualized, followed by automated cell detection with the manufacturer's software. Since this device offers very basic manual analysis, we did not prefer this approach in our study. The following parameters were obtained from the specular microscopy: mean cell density (cells $/ \mathrm{mm}^{2}$ ), coefficient of variation $(\mathrm{CV})$ in cell area, percentage of hexagonal cells, and central corneal thickness (CCT) in microns. Both glaucoma specialist and technician were masked from the results of other examinations.

\section{Statistical Analysis}

Statistical analysis was performed using a commercially available statistical software package (SPSS 23.0 for Windows, IBM-SPSS, Chicago, IL, USA). To assure statistical independence between eyes, only one eye of each subject was analyzed. If both eyes of a single subject were found to have same condition, the more severe eye based on presenting IOP was chosen. If both eyes had similar severity, then the study eye was randomly chosen. Normality test was performed using Kolmogorov-Smirnov testing method. Comparisons of ocular characteristics and corneal endothelial parameters across the angle closure subtypes were performed using 1-way ANOVA or Kruskal-Wallis test based on data distribution. Correlation of continuous data variables was analyzed using the Pearson or Spearman correlation test. Significance was set at $\mathrm{P}<0.05$ for this study.

\section{Results}

Fifty-two eyes from 52 subjects with chronic angle closure were included for analysis in the present study. Twentytwo (42.3\%) males and $30(57.7 \%)$ females comprised the study subjects with an age ranging from 40 to 74 years. The mean TIA was $13.7 \pm 6.8$ degree, while the mean ECD was $2479.4 \pm 396.5$ cells $/ \mathrm{mm}^{2}$.

Of the 52 subjects, 16 (30.8\%) had grade 1 TIA, 24 (46.2\%) had grade 2 TIA, and $12(23 \%)$ had grade 3 TIA. The demographic characteristics of these subjects are summarized in Table 1. Subjects with grade 1 TIA were significantly older than grade 3 TIA $(64.56 \pm 4.60$ vs $54.25 \pm$ 11.64, post hoc Bonferroni $P=0.007)$. Grade 1 TIA had a tendency of higher IOP compared to grade 2 and grade 3 $[29.5 \pm 8.8$ vs $25.7 \pm 9.5$ and $24.9 \pm 6.7$, respectively] although this was not statistically significant. There were no significant differences in the vertical cup-to-disk (CD) ratio, mean deviation, pattern deviation, and RNFL thickness between the groups.

We next analyze the correlation between TIA and presenting IOP as seen in Figure 1, and also correlation between TIA and age in Figure 2. TIA was not correlated with IOP but was modestly correlated with age (Spearman correlation $\mathrm{r}=-0.35 ; \mathrm{p}=0.01)$. 
Corneal endothelial cell parameters are compared in Table 2. We noted no significant differences in the mean central corneal ECD across the groups $(P=0.67)$. The $\mathrm{CV}$ was lowest in grade 3 TIA ( $36.4 \pm 7.2 \mu \mathrm{m} 2 /$ cell), and highest in grade 1 TIA $(38.3 \pm 9.6 \mu \mathrm{m} 2 /$ cell $)$, but the differences were not significant $(P=0.74)$. No significant difference was noted for hexagonality and CCT. Table 3 presents correlation of corneal parameters with age, TIA, and IOP at presentation. No significant correlation was observed.

\section{Discussion}

Our study demonstrated no association between the degree of ACA and corneal ECD and morphological characteristics such as $\mathrm{CV}$ and hexagonality in chronic angle closure. Interestingly, there was also no correlation between corneal endothelial status with age and presenting IOP.

AS-OCT can detect clinically important changes in the ACA structure in patients with angle-closure glaucoma. ${ }^{18}$ It allows for better diagnosis of angle-closure glaucoma given its ease of use, nonoperator dependence, and objective measurements. Studies showed AS-OCT has high diagnostic capability in detecting angle closure with higher sensitivity as compared to gonioscopy. ${ }^{15,19}$ In another recent study, using a modified Cirrus SD-OCT, the Schwalbe's line was identifiable in $95 \%$ of the scans and the scleral spur was identifiable in $85 \% .{ }^{20}$ Compared to SD-OCT, the SS-OCT has the ability to provide extremely high-resolution images. It has been shown to have accurate and reproducible measurements of peripheral anterior synechia (PAS) compared to the ordinary SD-OCT and gonioscopy. This may allow for an excellent method of monitoring risk assessment and PAS progression in the development of angle-closure glaucoma. ${ }^{21}$ The availability of SS-OCT could provide more extensive clinical data in the assessment of angle closure glaucoma. However, due to unattainability of the device, this study used SD-OCT for the assessment of ACA which provide adequate sensitivity and information.

Our study found an association between ACA and age which was in accordance with other studies. ${ }^{22-24}$ Increments of lens vault, iris curvature, iris thickness, and iris area with age led to a reduction in the dimensions of the anterior chamber and to narrowing of the ACA as demonstrated in a study by Sun et al. ${ }^{23}$ Another study by Bell et $\mathrm{al}^{24}$ also found that age-related positional changes in the ACA anatomy exist in normal healthy eyes. This may explain why aging is a significant risk factor for PACG.
However, we did not find an association between ACA and IOP. Studies have shown that IOP changes in chronic angle closure glaucoma were not merely associated with ACA, but also to the degree of PAS and damage of trabecular meshwork. ACA did not have a direct effect on the development and degree of PAS. Yoo et $\mathrm{al}^{25}$ demonstrated that $\mathrm{ACD}$, angle opening distance and trabecular-iris angle were not related to PAS. They stated that it was trabecular-ciliary process distance which had direct effect on PAS. The formation of PAS is a process which involves multiple mechanisms as an interplay effect of various factors such as high IOP, iris stickiness, iris contour, and other unidentified factors. Nevertheless, some studies found that significant PAS was observed in a small amount of PACG cases. ${ }^{26,27}$ Aung et $\mathrm{al}^{26}$ stated there was a possibility that drainage angle was not extensively closed by synechiae in majority of PACG cases in Asia. Sihota et $\mathrm{al}^{28}$ found damage on trabecular meshwork in chronic PACG even in areas where PAS were not observed. This explained why ACA alone did not have a direct effect on IOP.

Many recent studies with the interest on corneal endothelium in patients with angle closure focused on the effect of laser peripheral iridotomy or phacoemulsification..$^{29-35}$ In PACS, LPI does not appear to cause clinically significant corneal endothelial damage over 1, 3, and 6 years after treatment. ${ }^{29-32}$ However, Bansal et $\mathrm{al}^{33}$ demonstrated a significant endothelial cell loss at the treated site at a 6 monthfollow-up and suggested that Nd:YAG laser iridotomy may pose hazard to the corneal endothelium in patients with subacute angle closure. Studies have also been conducted to evaluate the effect of phacoemulsification on corneal endothelial cells in acute angle closure. Early phacoemulsification showed lower endothelial cell loss than did LPI in the treatment of APAC after a 2-year follow-up. ${ }^{34} \mathrm{~A}$ more recent study demonstrated that history of acute angle closure attack might not contribute to the exacerbation of corneal endothelial damage in cataract surgery. ${ }^{35}$

Few studies demonstrated the association between ACDand corneal endothelial cells, but none specifically discussed the effect of different degree of ACA on corneal ECD in chronic angle closure. Existing study was one by Varadaraj et $\mathrm{al}^{9}$ which found that lower ECD was observed in shallow $<2.5 \mathrm{~mm}$ ACD compared to deeper anterior chamber $\geq 2.5 \mathrm{~mm}$. Another study by Aoki et $\mathrm{al}^{36}$ also found thatACD was not a risk factor of endothelial cell loss, although their study was conducted in subjects with 
Table I Demographic Characteristics Across Different TIA Grading

\begin{tabular}{|l|l|l|l|l|}
\hline & \multicolumn{1}{|c|}{$\begin{array}{c}\text { Grade I TIA } \\
(\mathbf{n}=16)\end{array}$} & $\begin{array}{c}\text { Grade 2 TIA } \\
(\mathbf{n}=\mathbf{2 4})\end{array}$ & $\begin{array}{c}\text { Grade 3 TIA } \\
(\mathbf{n}=\mathbf{~ I 2 )}\end{array}$ & \multicolumn{1}{|c|}{ P value } \\
\hline Age (years) & $64.56 \pm 4.60$ & $58.04 \pm 8.44$ & $54.25 \pm 11.64$ & $<0.01 *$ \\
IOP (mmHg) & $26.65(21-48)$ & $23.40(21-66)$ & $23.10(21-45)$ & $0.10^{* *}$ \\
Vertical CD ratio & $0.75 \pm 0.10$ & $0.69 \pm 0.17$ & $0.67 \pm 0.18$ & $0.36 *$ \\
Mean deviation & $-16.25 \pm 1.24$ & $-4.43(-32.27-2.17)$ & $-8.24(-33.63-0.35)$ & $0.08 * *$ \\
Pattern standard deviation & $3.42(1.16-12.57)$ & $3.18(1.18-12.48)$ & $4.57 \pm 3.73$ & $0.86 * *$ \\
RNFL thickness & $75.56 \pm 18.12$ & $84.0 \pm 25.06$ & $75.83 \pm 22.02$ & $0.42^{*}$ \\
\hline
\end{tabular}

Notes: *One-way ANOVA test; **Kruskal-Wallis test; significance is indicated with bold.

Abbreviations: CD, cup-to-disk; IOP, intraocular pressure; RNFL, retinal nerve fiber layer; TIA, trabecular iris angle.

pseudoexfoliation. We did not find any association between the degree of ACA and corneal ECD or morphological characteristics. Our findings might reflect that varying degree of shallow anterior chamber did not show significant difference of corneal endothelial cell damage.

Intriguingly, we also did not find an association between age and ECD or other endothelial morphological characteristics. Previous studies showed significant correlation between ECD and age, but their studies were conducted in a population with a wider age range, from 20 to 85 years. $^{37,38}$ Our study had relatively narrowrange, from
40 to 74 years, which might be related to the insignificant association between age and ECD.

The relationship between glaucoma and corneal endothelial characteristics has not been established conclusively. There were conflicting reports on the effect of elevated IOP on the ECD. Our study comprised exclusively of subjects with angle closure without previous acute attack. This allowed a more homogeneous comparison as all subjects did not show signs of previous dramatic IOP increase which would have its own impact on corneal endothelium.

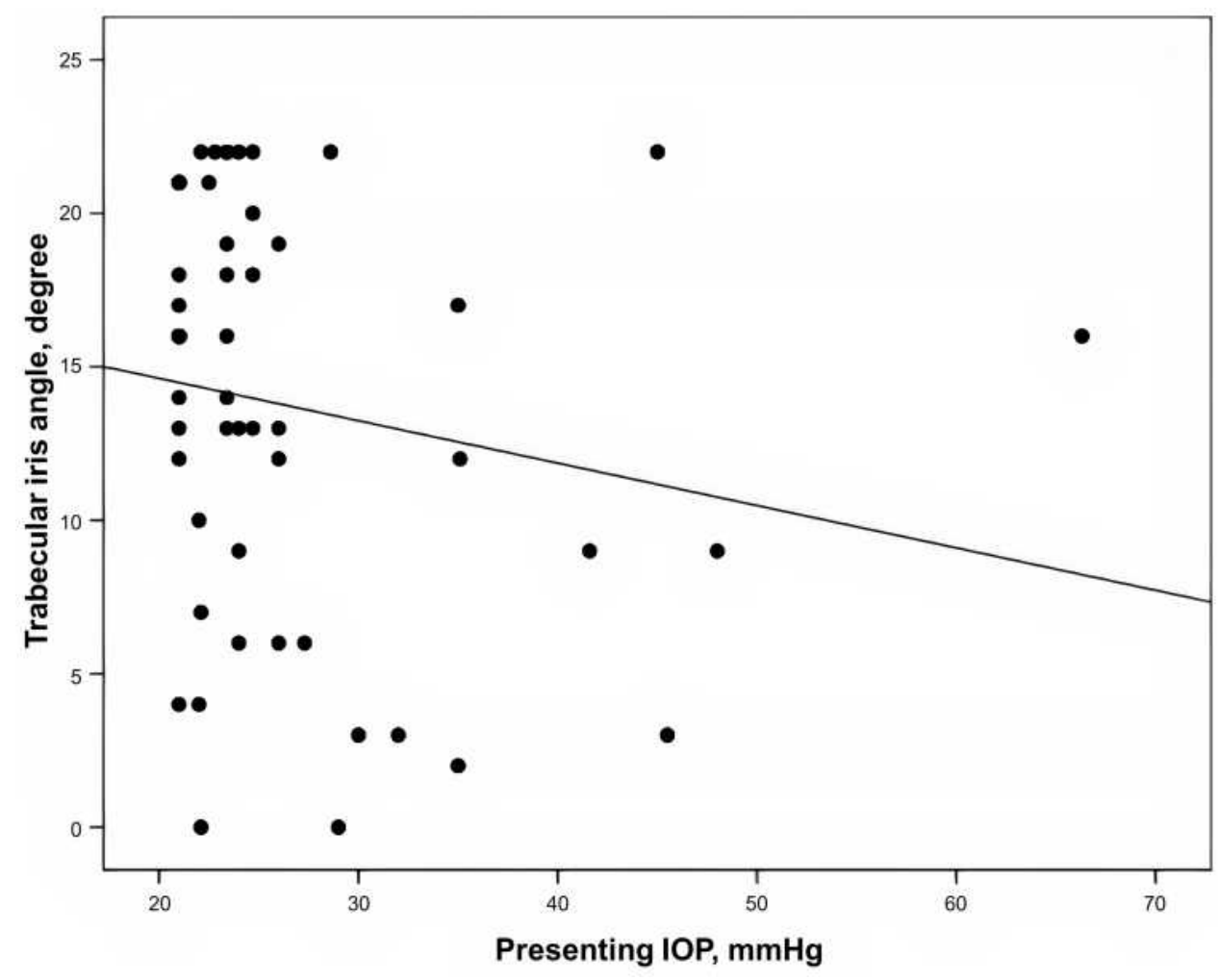

Figure I Scatter plot of trabecular iris angle and presenting intraocular pressure (Spearman correlation $r=-0.24 ; P=0.09$ ). 


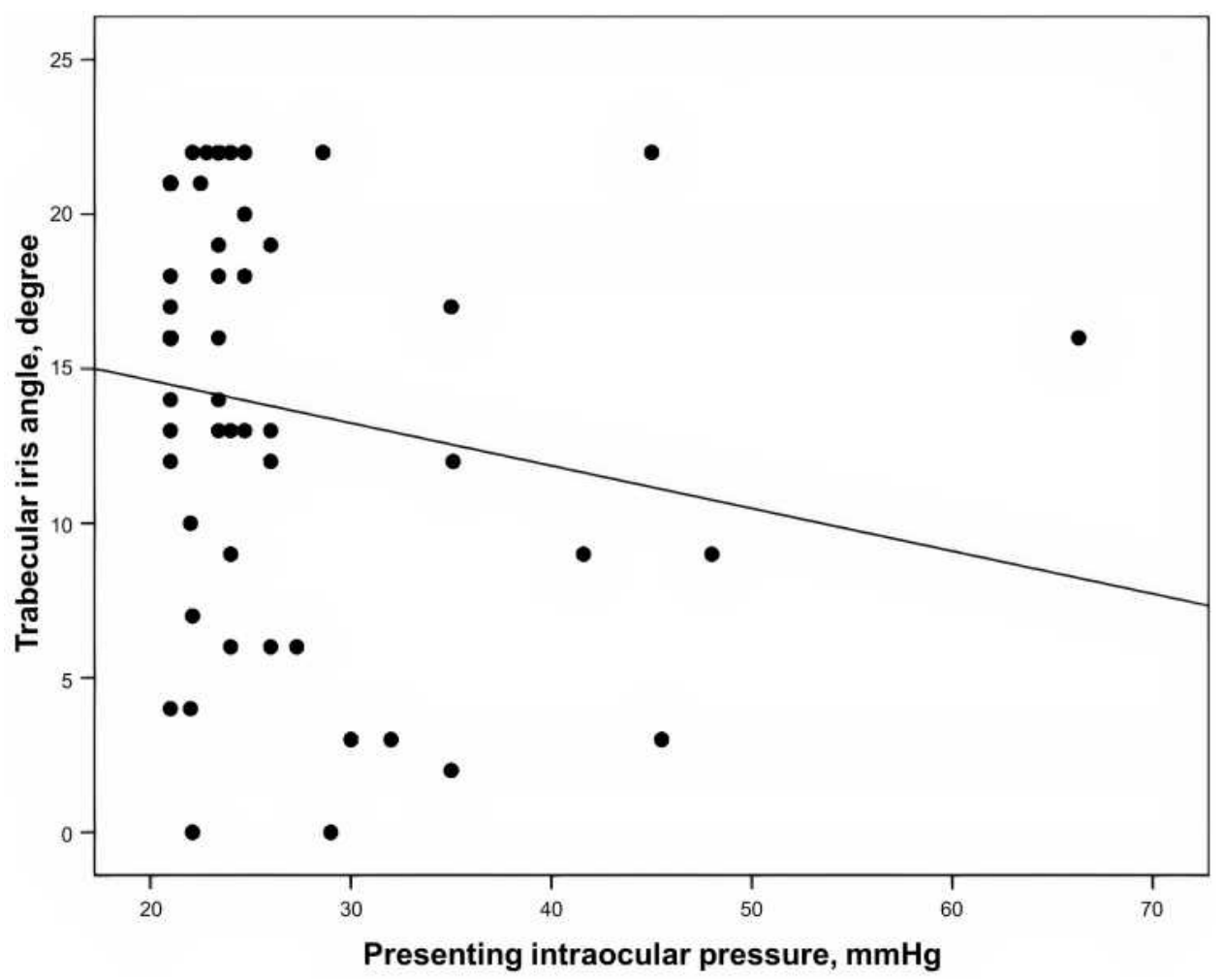

Figure 2 Scatter plot of trabecular iris angle and age (Spearman correlation $r=-0.35 ; P=0.01$ ).

Our finding of insignificant correlation between IOP and ECD or other corneal endothelial morphological characteristics were similar to a study by Verma et $\mathrm{al}^{10}$ which also did not find any correlation between the two. In their study, all subjects had optimally controlled IOP. This supported the statement that the lack of sudden and dramatic IOP increase would not have a direct impact on corneal endothelial damage.

The strength of our study was that it was comprised of subjects who were all treatment-naïve without prior history of glaucoma medication, laser intervention, or surgical procedures including phacoemulsification, thus allowing a more uniform comparison. Another strength was the unique assessment of ECD in chronic angle closure without history of acute attack. A correlation between duration of raised IOP and ECD loss has been established. ${ }^{3,4}$ Phacoemulsification was also known to induce a change in ACD and TIA which depended on the characteristics of the eye structure. ${ }^{39}$ However, to the best of our knowledge, there are no studies that sought to assess the association between varying degree of ACA and ECD specifically in chronic angle closure. Our study helps better understand the possible mechanism which contributes to corneal endothelial cell loss in angle closure. The degree of ACA in angle closure, without the occurrence of acute attack, were not found to correlate with ECD.

One of the study limitations was the relatively small sample size and cross-sectional nature of the study; hence

Table 2 Corneal Parameters Across Different TIA Grading

\begin{tabular}{|l|l|l|l|l|}
\hline & \multicolumn{1}{|c|}{$\begin{array}{c}\text { Grade I TIA } \\
(\mathbf{n}=16)\end{array}$} & \multicolumn{1}{|c|}{$\begin{array}{c}\text { Grade 2 TIA } \\
(\mathbf{n}=\mathbf{2 4})\end{array}$} & $\begin{array}{c}\text { Grade 3 TIA } \\
(\mathbf{n}=12)\end{array}$ \\
\hline ECD $\left(\right.$ cells $\left./ \mathrm{mm}^{2}\right)$ & $2684.5(1433-2934)$ & $2587.0(1902-3103)$ & $2441.0(1659-3005)$ & $0.67 *$ \\
CV $\left(\mu \mathrm{m}^{2} / \mathrm{cell}\right)$ & $38.3 \pm 9.6$ & $36.6 \pm 6.6$ & $36.4 \pm 7.2$ & $0.74 *$ \\
Hexagonality $(\%)$ & $51.6 \pm 8.3$ & $49.8 \pm 11.9$ & $52.4 \pm 10.7$ & $0.73^{*}$ \\
CCT (microns) & $538.6 \pm 45.4$ & $541.9 \pm 29.9$ & $551.9 \pm 26.6$ & $0.59 * *$ \\
\hline
\end{tabular}

Notes: *Kruskal-Wallis test; **one-way ANOVA test.

Abbreviations: CCT, central corneal thickness; CV, coefficient of variance; ECD, endothelial cell density; TIA, trabecular iris angle. 
Table 3 Correlation of ECD, CV, Hexagonality, and CCT with Other Variables

\begin{tabular}{|l|l|l|l|}
\hline $\begin{array}{l}\text { Corneal } \\
\text { Parameters }\end{array}$ & \multicolumn{1}{|c|}{ Age } & \multicolumn{1}{|c|}{$\begin{array}{c}\text { Trabecular Iris } \\
\text { Angle }\end{array}$} & $\begin{array}{c}\text { Presenting } \\
\text { IOP }\end{array}$ \\
\hline ECD correlation & $-0.06^{*}$ & $-0.13^{*}$ & $0.07^{*}$ \\
\hline Sig. (2-tailed) & 0.67 & 0.35 & 0.61 \\
\hline CV correlation & $-0.18^{* *}$ & $-0.09^{*}$ & $0.01 *$ \\
\hline Sig. (2-tailed) & 0.40 & 0.51 & 0.99 \\
\hline $\begin{array}{l}\text { Hexagonality } \\
\text { correlation }\end{array}$ & $0.03^{* *}$ & $-0.01 *$ & $<0.01^{*}$ \\
\hline Sig. (2-tailed) & 0.86 & 0.93 & 0.98 \\
\hline CCT correlation & $-0.19^{* *}$ & $0.11^{*}$ & $<0.01^{*}$ \\
\hline Sig. (2-tailed) & 0.18 & 0.46 & 0.98 \\
\hline
\end{tabular}

Notes: *Spearman correlation; **pearson correlation; correlation is significant at 0.05 level (2-tailed).

Abbreviations: CCT, central corneal thickness; CV, coefficient of variance; $E C D$, endothelial cell density; IOP, intraocular pressure.

it is difficult to establish temporal relationships. Secondly, the actual duration of the disease was not known. It was difficult to identify how long the subjects have been in certain level of IOP increase as this might affect the corneal endothelium as well. Lastly, ECD is an indirect measure of corneal function and may not reflect the overall corneal status, and we were limited by the nonavailability of data on peripheral corneal endothelium.

\section{Conclusion}

Our study has shown that corneal ECD and its morphological characteristics were not significantly different across varying TIA grading in chronic angle closure. TIA was also not correlated with IOP. These findings may corroborate that chronic gradual IOP increase with the lack of abrupt IOP insult would not have direct effect on corneal endothelium in our study group. Long-term prospective studies are needed to better understand the corneal ECD and morphological characteristics on varying degree of ACA.

\section{Acknowledgments}

The authors wish to thank Nina Asrini Noor for her writing assistance, technical editing, and language editing of this manuscript.

\section{Disclosure}

The authors report no conflicts of interest in this work.

\section{References}

1. Sihota R, Lakshmaiah NC, Titiyal JS, Dada T, Agarwal HC. Corneal endothelial status in the subtypes of primary angle closure glaucoma. Clin Experiment Ophthalmol. 2003;31(6):492-495. doi:10.1046/ j.1442-9071.2003.00710.x

2. Tham CC, Kwong YY, Lai JS, Lam DS. Effect of a previous acute angle closure attack on the corneal endothelial cell density in chronic angle closure glaucoma patients. J Glaucoma. 2006;15(6):482-485. doi:10.1097/01.ijg.0000212273.73100.31

3. Setälä K. Corneal endothelial cell density after an attack of acute glaucoma. Acta Ophthalmol. 1979;57(6):1004-1013. doi:10.1111/ j.1755-3768.1979.tb00531.x

4. Bigar F, Witmer R. Corneal endothelial changes in primary acute angle closure glaucoma. Ophthalmology. 1982;89(6):596-599. doi:10.1016/S0161-6420(82)34744-2

5. Malaise-Stals J, Collignon-Brach J, Weekers JF. Corneal endothelial cell density in acute angle closure glaucoma. Ophthalmologica. 1984;189(3):104-109. doi:10.1159/000309393

6. Korey M, Gieser D, Kass MA, Waltman SR, Gordon M, Becker B. Central corneal endothelial cell density and central corneal thickness in ocular hypertension and primary open angle glaucoma. Am $J$ Ophthalmol. 1982;94(5):610-616. doi:10.1016/0002-9394(82) 90005-8

7. Li X, Zhang Z, Ye L, et al. Acute ocular hypertension disrupts barrier integrity and pump function in rat corneal endothelial cells. Sci Rep. 2017;7:6951. doi:10.1038/s41598-017-07534-9

8. Sandoval HP, Al Sarraf O, Vroman DT, Solomon KD. Corneal endothelial cell damage after lens extraction using the fluid-based system compared to ultrasound phacoemulsification in human cadaver eyes. Cornea. 2004;23(7):720-722. doi:10.1097/01. ico.0000130184.56514.51

9. Varadaraj V, Sengupta S, Palaniswamy K, et al. Evaluation of angle closure as a risk factor for reduced corneal endothelial cell density. J Glaucoma. 2017;26(6):566-570. doi:10.1097/ IJG.0000000000000669

10. Verma S, Nongpiur ME, Husain R, et al. Characteristics of the corneal endothelium across the primary angle closure disease spectrum. Invest Ophthalmol Vis Sci. 2018;59(11):4525-4530. doi:10.1167/iovs.18-24939

11. Riva I, Micheletti E, Oddone F, et al. Anterior chamber angle assessment techniques: a review. $J$ Clin Med. 2020;9(12):3814. doi: $10.3390 /$ j $\mathrm{cm} 9123814$

12. Konstantopoulos A, Hossain P, Anderson DF. Recent advances in ophthalmic anterior segment imaging: a new era for ophthalmic diagnosis? $\mathrm{Br} J$ Ophthalmol. 2007;91(4):551-557. doi:10.1136/ bjo.2006.103408

13. Lim SH. Clinical applications of anterior segment optical coherence tomography. J Ophthalmol. 2015;2015:605729. doi:10.1155/2015/ 605729

14. Napoli PE, Nioi M, Mangoni L, et al. Fourier-domain OCT imaging of the ocular surface and tear film dynamics: a review of the state of the art and an integrative model of the tear behavior during the inter-blink period and visual fixation. J Clin Med. 2020;9(3):668. doi: $10.3390 / \mathrm{jcm} 9030668$

15. Nolan WP, See JL, Chew PT, et al. Detection of primary angle closure using anterior segment optical coherence tomography in Asian eyes. Ophthalmology. 2007;114(1):33-39. doi:10.1016/j. ophtha.2006.05.073

16. Ho SW, Baskaran M, Zheng C, et al. Swept source optical coherence tomography measurement of the iris-trabecular contact (ITC) index: a new parameter for angle closure. Graefes Arch Clin Exp Ophthalmol. 2013;251(4):1205-1211. doi:10.1007/s00417-0122158-6 
17. Porporato N, Baskaran M, Husain R, Aung T. Recent advances in anterior chamber angle imaging. Eye. 2020;34(1):51-59. doi:10.1038/s41433-019-0655-0

18. Masoodi H, Jafarzadehpur E, Esmaeili A, Abolbashari F, Ahmadi Hosseini SM. Evaluation of anterior chamber angle under dark and light conditions in angle closure glaucoma: an anterior segment OCT study. Cont Lens Anterior Eye. 2014;37(4):300-304. doi:10.1016/j. clae.2014.04.002

19. Nongpiur ME, Haaland BA, Perera SA, et al. Development of a score and probability estimate for detecting angle closure based on anterior segment optical coherence tomography. Am J Ophthalmol. 2014;157 (1):32-38.e1. doi:10.1016/j.ajo.2013.09.012

20. Cheung CY, Zheng C, Ho CL, et al. Novel anterior-chamber angle measurements by high-definition optical coherence tomography using the schwalbe line as the landmark. $\mathrm{Br} J$ Ophthalmol. 2011;95 (7):955-959. doi:10.1136/bjo.2010.189217

21. Lai I, Mak H, Lai G, Yu M, Lam DS, Leung CK. Anterior chamber angle imaging with swept-source optical coherence tomography: measuring peripheral anterior synechia in glaucoma. Ophthalmology. 2013;120(6):1144-1149. doi:10.1016/ j.ophtha.2012.12.006

22. Cheon MH, Sung KR, Choi EH, et al. Effect of age on anterior chamber angle configuration in Asians determined by anterior segment optical coherence tomography; clinic-based study. Acta Ophthalmol. 2010;88(6):e205-e210. doi:10.1111/j.1755-3768.2010.01960.x

23. Sun JH, Sung KR, Yun SC, et al. Factors associated with anterior chamber narrowing with age: an optical coherence tomography study. Invest Ophthalmol Vis Sci. 2012;53(6):2607-2610. doi:10.1167/ iovs.11-9359

24. Bell NP, Nagi KS, Cumba RJ, et al. Age and positional effect on the anterior chamber angle: assessment by ultrasound biomicroscopy. ISRN Ophthalmol. 2013;2013:706201. doi:10.1155/2013/706201

25. Yoo C, Oh JH, Kim YY, Jung HR. Peripheral anterior synechiae and ultrasound biomicroscopic parameters in angle-closure glaucoma suspects. Korean J Ophthalmol. 2007;21(2):106-110. doi:10.3341/ kjo.2007.21.2.106

26. Aung T, Lim MC, Chan YH, Rojanapongpun P, Chew PT; EXACT Study Group. Configuration of the drainage angle, intraocular pressure, and optic disc cupping in subjects with chronic angle-closure glaucoma. Ophthalmology. 2005;112(1):28-32. doi:10.1016/j. ophtha.2004.06.033

27. Liu CJ, Cheng CY, Wu CW, Lau LI, Chou JC, Hsu WM. Factors predicting intraocular pressure control after phacoemulsification in angle-closure glaucoma. Arch Ophthalmol. 2006;124(10):1390-1394. doi:10.1001/archopht.124.10.1390

28. Sihota R, Lakshmaiah NC, Walia KB, Sharma S, Pailoor J, Agarwal HC. The trabecular meshwork in acute and chronic angle closure glaucoma. Indian J Ophthalmol. 2001;49(4):255-259.
29. Liao C, Zhang J, Jiang Y, et al. Long-term effect of YAG laser iridotomy on corneal endothelium in primary angle closure suspects: a 72-month randomised controlled study. Br J Ophthalmol. 2021;105 (3):348-353. doi:10.1136/bjophthalmol-2020-315811

30. Jamali H, Jahanian S, Gharebaghi R. Effects of laser peripheral iridotomy on corneal endothelial cell density and cell morphology in primary angle closure suspect subjects. J Ophthalmic Vis Res. 2016;11(3):258-262. doi:10.4103/2008-322X.188395

31. Kumar RS, Baskaran M, Friedman DS, et al. Effect of prophylactic laser iridotomy on corneal endothelial cell density over 3 years in primary angle closure suspects. $B r \quad J$ Ophthalmol. 2013;97 (3):258-261. doi:10.1136/bjophthalmol-2012-302013

32. Sihota R, Agarwal E, James M, et al. Long-term evaluation of specular microscopic changes following $\mathrm{Nd}$ : YAG iridotomy in chronic primary angle-closure glaucoma eyes. J Glaucoma. 2017;26 (9):762-766. doi:10.1097/IJG.0000000000000704

33. Bansal N, Aggarwal A, Kaur P, Bedi J, Jeria S, Gusain P. A study of endothelial cell count pre- and post-neodymium-doped yttrium aluminum garnet laser iridotomy in subacute angle closure using specular microscope. Taiwan J Ophthalmol. 2019;9(2):104-110. doi:10.4103/tjo.tjo_38_18

34. Park HY, Lee NY, Park CK, Kim MS. Long-term changes in endothelial cell counts after early phacoemulsification versus laser peripheral iridotomy using sequential argon: YAGlaser technique in acute primary angle closure. Graefes Arch Clin Exp Ophthalmol. 2012;250 (11):1673-1680. doi:10.1007/s00417-012-1998-4

35. Yeom H, Hong EH, Shin YU, Kang MH, Cho HY, Seong M. Corneal endothelial cell loss after phacoemulsification in eyes with a prior acute angle-closure attack. Korean $J$ Ophthalmol. 2020;34 (6):432-438. doi:10.3341/kjo.2020.0040

36. Aoki $\mathrm{T}$, Kitazawa $\mathrm{K}$, Inatomi $\mathrm{T}$, et al. Risk factors for corneal endothelial cell loss in patients with pseudoexfoliation syndrome. Sci Rep. 2020;10(1):7260. doi:10.1038/s41598-020-64126-w

37. Arıcı C, Arslan OS, Dikkaya F. Corneal endothelial cell density and morphology in healthy Turkish eyes. $J$ Ophthalmol. 2014;2014:852624. doi:10.1155/2014/852624

38. Hashemian MN, Moghimi S, Fard MA, Fallah MR, Mansouri MR. Corneal endothelial cell density and morphology in normal Iranian eyes. BMC Ophthalmol. 2006;6:9. doi:10.1186/1471-2415-6-9

39. Rękas M, Barchan-Kucia K, Konopińska J, Mariak Z, Żarnowski T. Analysis and modeling of anatomical changes of the anterior segment of the eye after cataract surgery with consideration of different phenotypes of eye structure. Curr Eye Res. 2015;40(10):1018-1027. doi: $10.3109 / 02713683.2014 .975366$
Clinical Ophthalmology

\section{Publish your work in this journal}

Clinical Ophthalmology is an international, peer-reviewed journal covering all subspecialties within ophthalmology. Key topics include: Optometry; Visual science; Pharmacology and drug therapy in eye diseases; Basic Sciences; Primary and Secondary eye care; Patient Safety and Quality of Care Improvements. This journal is indexed on PubMed

\section{Dovepress}

Central and CAS, and is the official journal of The Society of Clinical Ophthalmology (SCO). The manuscript management system is completely online and includes a very quick and fair peer-review system, which is all easy to use. Visit http://www.dovepress.com/ testimonials.php to read real quotes from published authors. 